\title{
Monitoring the evolution of posttraumatic symptomatology, depression and anxiety during the COVID-19 pandemic in Brazilians (COVIDPsiq)
}

Vitor Crestani Calegaro ( $\square$ vitor.calegaro@ufsm.br)

UFSM https://orcid.org/0000-0001-8697-0267

Bianca Lorenzi Negretto

UFSM https://orcid.org/0000-0003-4067-9786

Leopoldo Pompeo Weber

UFSM https://orcid.org/0000-0001-9776-9585

Natalia Kerber

UFSM https://orcid.org/0000-0001-7158-7003

Gustavo Zoratto

UFSM https://orcid.org/0000-0003-0674-867X

Leonardo Rodrigues

UFSM https://orcid.org/0000-0002-3155-4642

Luiza Elizabete Braun

UFSM https://orcid.org/0000-0002-9218-0429

Julia Kochler

UFSM https://orcid.org/0000-0001-7181-6523

Fernando Leite Girardi

UFSM https://orcid.org/0000-0002-1398-6097

Vitor Daniel Picinin

UFSM https://orcid.org/0000-0002-9547-1475

Luísa Maciel

UFSM https://orcid.org/0000-0001-5399-6559

Gabriel Salomão Labre

UFSM https://orcid.org/0000-0002-9396-9229

Fernanda Coloniese Dala Costa

UFSM https://orcid.org/0000-0003-0889-8532

\section{Method Article}

Keywords: Pandemics, Psychological Stress, Depression, Post Traumatic Stress Disorder, Anxiety disorders 
Posted Date: December 9th, 2020

DOI: https://doi.org/10.21203/rs.3.pex-945/v2

License: (c) (i) This work is licensed under a Creative Commons Attribution 4.0 International License. Read Full License 


\section{Abstract}

In view of the evolution of the pandemic by COVID-19 in Brazil, and the adoption of social restriction measures, an increase in cases of posttraumatic stress disorder (PTSD), anxiety disorder and depression is expected. In epidemic situations, mental health services can become overloaded; however, the evolution of these disorders over time is not known. This study aims to monitor the evolution of PTSD symptoms, anxiety and depression during the COVID-19 pandemic in Brazilians, and to investigate sociodemographic risk factors related to psychiatric history and contagion, as well as maladaptive personality traits and posttraumatic growth. It will be a longitudinal study, conducted through online questionnaires, with a sample of non-probabilistic convenience. The inclusion criteria are: being brazilian born or living in Brazilian territory; be over 18 years old; have access to digital devices; and be literate. A sample of at least 2000 people is expected. The instruments applied are a research questionnaire, the Posttraumatic Checklist 5 (PCL-5), the Depression, Anxiety and Stress Scale (DASS-21), the Personality Inventory for the DSM-5 - brief form (PID-5-BF), and the PostTraumatic Growth Inventory (PTGI). The study will be carried out in four stages: entry, one month, three months, and six months after the entry. The study relies on voluntary participation, with the agreement through the Free and Informed Consent Form. Data collection will be conducted in 2020, and the study will be completed in 2021. It will be financed with its own resources, and encouragement will be sought through research funding agencies.

\section{Introduction}

\section{INTRODUCTION}

In December 2019, the first case of coronavirus disease (COVID-19) was reported in China, which initiated the largest outbreak of atypical pneumonia since severe acute respiratory syndrome (SARS) in 2003 (WANG et al., 2020). The disease was not limited to Chinese territory; it exponentially spread across five continents and, on March 11, was declared a pandemic (WORLD HEALTH ORGANIZATION, 2020). According to data from Johns Hopkins University, on March 29, 2020 the virus had already infected 704,095 people worldwide and caused 33,509 deaths, with 3,904 infections and 117 deaths just in Brazil (JHU, 2020).

The occurrence of great morbidity and mortality in the population, together with the economic losses resulting from a pandemic, leads to a huge psychosocial risk, generating an urgent demand for mental health care (XIANG et al., 2020). Recognizing this vulnerability in different risk groups (including infected people, family members and health professionals) is necessary for an optimized approach to material and human resources, as local services get overwhelmed (SHIGEMURA et al., 2020). The safety and habitual functioning of society are destabilized, generating an anxiety and suffering that affect the 
population as a whole, in different degrees. Fear, uncertainty and stigma are common and can become barriers in searching for care.

Due to the rapid spread, in the presence of diseases with high rates of transmissibility, government efforts focus on avoiding contagion by instituting epidemiological containment measures - such as social isolation, for example. However, as a public health emergency, the focus during epidemics has been the fight against infection, and emotional overload triggers mental disorders often neglected (ORNELL et al., 2020). In this context, studies reveal that the implications of pandemics, as well as the measures taken, have an important repercussion on mental health. This was the case of SARS, contained by quarantine measures, which resulted in a prevalence of $28.9 \%$ of symptomatology of posttraumatic stress disorder (PTSD) in the city of Toronto, Canada (HAWRYLUCK et al., 2004).

Concomitantly with the expansion of the outbreak, psychological distress also increases, especially with regard to stress symptoms, and may trigger PTSD when an individual experiences the possibility of death by COVID, either in himself or in a loved one (SUN et al., 2020). PTSD is characterized by intrusive symptoms (such as recurrent and distressing memories, nightmares and flashbacks),phobic avoidance, depressive and anxious symptoms, negative beliefs, behavioral changes, and irritability, which can become chronic if not properly diagnosed and treated (AMERICAN PSYCHIATRIC ASSOCIATION, 2014). An observational study conducted in China in the three days following the COVID-19 declaration as a public health emergency of international interest revealed that $58.8 \%$ of the participating population considered the psychological impact of the outbreak to be moderate to severe and $8.1 \%$ reported moderate to severe stress levels (WANG et al., 2020).

In addition to PTSD, it is possible to observe the appearance of cases of depression and anxiety disorders, in addition to the worsening of previous mental disorders. Thus, this work aims to monitor the evolution of symptomatology of posttraumatic stress, depression and anxiety during the covid-19 pandemic in Brazilians, determine risk factors and evaluate posttraumatic growth after six months.

\section{JUSTIFICATION}

The number of CASES of COVID-19 in Brazil is growing alarmingly and measures to contain the spread of the virus have already been imposed in most of the country. An increase in mental disorders is expected, especially PTSD, which is commonly associated with other disorders, can lead to suicidal behavior, also causing a great socioeconomic impact and quality of life (SHIGEMURA et al., 2020).

Given the current pandemic scenario by SARS-CoV-2 (severe acute respiratory syndrome virus 2), the etiological agent of COVID-19, as well as epidemiological containment measures such as quarantine and social isolation, it is essential to document and evaluate possible psychological repercussions. For this, it seeks to record such repercussions in as many people as possible, in a safe and accessible way.

The monitoring of mental illness will allow the identification of the demand for mental health services in real time. The research information will provide support for the planning and executing of interventions. 
The study of sociodemographic risk factors may identify people more vulnerable to psychological illness for the creation of actions directed to the groups at higher risk. The study of personality traits associated with risk will bring long-term benefits by identifying individuals with a higher probability of mental illness, assisting in the planning of resilience reinforcement interventions, in schools, universities and in companies, for example.

\section{GOALS}

\section{Overall objective}

To monitor the evolution of PTSD symptomatology, depression and anxiety in a sample of Brazilians during the COVID-19 pandemic, and to identify sociodemographic risk factors related to maladaptive personality traits.

\section{Specific objectives}

- To identify patterns of evolution (trajectories) of PTSD symptoms;

- To document and report in real time the sample prevalence and severity of PTSD symptoms in the beginning, during, and in the decline of the pandemic;

- To verify sociodemographic risk factors related to the maladaptive personality traits associated with the trajectories of PTSD symptoms;

- To check the stability of the maladaptive traits of the personality during the pandemic, that is, to prove that such traits remain stable even during life events, or not;

- To relate the symptomatology with variables attributed to exposure to COVID19, such as contact with cases, having contracted the disease, being in regions of high incidence, being in quarantine/social isolation and others;

- To compare symptoms presented by professionals who could not be quarantined during the indicated period (professionals from key areas such as health, cleaning, food, delivery sector, etc.), with individuals who were quarantined;

- To relate posttraumatic growth to PTSD trajectories and personality traits.

\section{Reagents}

\section{Equipment}

The survey will be conducted through the SurveyMonkey virtual platform. It will have four stages, in which customized quesions and validated questionnaires will be applied. The following research instruments will be used, all self-applicable, translated and validated to Brazilian Portuguese: 
- Research questionnaire (Appendix I: developed by the researchers, contains general questions, including sociodemographic factors, related to mental health treatments, and information related to the pandemic.

- Posttraumatic Stress Disorder Checklist 5 (PCL-5; Annex II). It is a 20-item self-answered questionnaire, which can be used for screening patients with PTSD and monitoring the severity of symptoms over time (LIMA et al., 2016). The psychometric properties of PCL-5 have high sensitivity and specificity. A score of 38 , out of a maximum of 80 , is associated with the diagnosis of PTSD (BLEVINS et al., 2015).

- Depression, Anxiety and Stress Scale (DASS-21; Annex III). Likert scale of 21 items, ranging from 0 (strongly disagree) to 3 (strongly agree), is divided into three domains: depression, anxiety and stress. It measures the severity of each domain, and provides a total score. The development of the scale started from the model that stress is implicated in depression and anxiety, being a common component in both (VIGNOLA; TUCCI, 2014).

- Personality Inventory for DSM-5 - brief form (PID-5-BF; Annex IV). There are 25 questions that inform about five maladaptive personality traits: negative affectivity, detachment, antagonism, disinhibition and psychoticism (KRUEGER et al., 2013). It has been validated in a variety of countries, including Brazil (ZATTI et al., 2020). It evaluates the severity of the traits using a five-point Likert scale, whose score is associated with the severity of the psychopathology of the personality in general.

Post-Traumatic Growth Inventory (PTGI). It is an instrument that aims to quantify the experience of growth and positive changes after traumatic situations. It has 21 items on a six-point Likert scale, and five dimensions: better appreciation of life and changing goals and priorities; improvement in interpersonal relationships and intimacy; recognition of new possibilities for living life; greater sense of strength; and changes in spirituality (SILVA et al., 2018).

\section{Procedure}

Study Design - Observational, longitudinal and prospective study (cohort), with six months of follow-up. Data will be collected at T0 (start), T1 (one month later), T2 (three months later), and T3 (six months later). The design allows cross-sectional and nested case-control studies.

Population and sample - It will be a sample of convenience, non-probabilistic. The snowball sampling technique, in which each individual indicates other individuals, and so on, up to the point of saturation (at which the individuals begin to repeat themselves), will be employed. We seek as much reach as possible, using online questionnaires, made available through digital platforms (WhatsApp, email, Facebook and Instagram). The collaboration of communication vehicles, psychiatric medical entities and government agencies will be sought. The inclusion criteria are: to be Brazilian or reside in Brazil; to be over 18; have access to digital devices; and to be literate. Incomplete questionnaires or those in which a valid email address has not been provided will be excluded. The estimated sample size is at least 2,000 subjects, enough for the type of analysis sought. 
Procedures - The survey will be conducted through the SurveyMonkey virtual platform. The link to the survey will be widely disseminated through social networks and via email contacts. Support from the press will be requested for dissemination in order to expand the scope of the research. The questionnaires will be answered anonymously; however, an email address will be requested to enable the survey to be followed. The first page contains the Informed Consent Term (ICT), with verification of the inclusion criteria. According to the participation, the research subject starts to answer the research instruments, according to the research stage:

T0: research questionnaire, PCL-5, DASS-21 and PID-5;

- T1: research questionnaire (specific part related to coronavirus infection), PCL-5 and DASS-21.

T2: research questionnaire (specific part related to coronavirus infection), PCL-5 and DASS-21.

- T3: research questionnaire (specific part related to coronavirus infection), PCL-5, DASS-21, PID-5 and PTGI.

From the virtual platform, each step will generate, in real time, the score of the PCL-5 and DASS-21 scales, in order to inform the subject about their mental health status. This feedback is intended to benefit the participant, informing them of the need to seek mental health care, and at the same time informing them of the referral services available in the Unified Health System. This strategy also seeks greater engagement for further research.

Data analysis - The collected data will be stored on the SurveyMonkey server, with exclusive access through the account of the responsible researcher (Vitor Calegaro). For data analysis, SPSS v applications will be used. 23, MPlus v.7.01, and R v.1.2.1355. The analysis will be carried out in stages: univariate, bivariate and multivariate.

In the first stage, the treatment of the data is sought, as well as the verification of normality (mean, median, standard deviation, kurtosis, asymmetry and Kolmogorov-Smirnov and Shapiro-Wilk tests), and analysis of missing values (missings) . In bivariate analysis, correlation analysis and comparison of means (or medians) with parametric or non-parametric tests will be used. Categorical variables will be compared using the Chi-square test and Fisher's exact test.

For the analysis of symptom trajectories, latent growth analysis (LGA) will be used, a technique that groups individuals in similar patterns of item responses over time. For this, the MPlus and R software (MplusAutomation package) will be used. Thus, models are firstly constructed from a latent class $(\mathrm{HO})$, up to the number of classes in which the parameters are valid, or that the class with the lowest number has at least $20 \%$ of the individuals. Next, the parameters are compared in order to find the one that best fits the data. In the next step, the probability of belonging to each of the classes is attributed to each individual, and afterwards, multinomial logistic regression techniques are used to determine risk factors for each trajectory (DAYTON, 2008). 
Ethical issues - The research will bring direct benefits to the participant, informing about the need to seek mental health care when the individual has warning symptoms. At the end of completing the research form, the participant will be directed to a page with links from official agencies (World Health Organization, Brazilian Psychiatric Association, Federal Council of Psychology, among others), with recommendations on mental health. These general guidelines include sleep hygiene, encouraging physical exercise, and avoiding substance abuse, for example.

In addition, this study will contribute to a greater understanding of the psychic repercussion of quarantine and social isolation in the face of the COVID-19 pandemic, and will present real-time data that show (or not) the expansion of the health care network mental, bringing indirect benefit to the participant.

The only risk the study refers to its possible psychological discomfort when answering the questionnaires. As a precautionary and protective measure, we will provide links and information from the Ministry of Health regarding the mental health services available, as well as ways of accessing the Unified Health System, an accredited network and telemedicine. The information will be contained on the website that is being prepared for the dissemination of the research, in a didactic and accessible way, containing telephone numbers (for example, CVV - 188; Dial 180, from the Secretariat of Policies for Women, for complaints of violence), links to government websites and other information needed to seek help. This page is currently being prepared, and will be made available through a specific link, displayed on the final page of the questionnaire. In addition, the researchers make themselves available to the participants, via email, for contact if the participant needs it. In-depth questions will not be asked with respect to traumatic events, so the benefits are thought to outweigh the risks. A meta-analysis of 70 studies on psychological trauma, regarding the reactions of participants when responding to research, showed that the discomfort, in general, is not extreme, being greater when there is an interview, and that the subjects report participation as positive, even with a history of PTSD (JAFFE et al., 2015).

Entry into the study will only be possible after the subject has read and agreed to the IC. The identification of the subject will be done exclusively by email address. The responsible researcher is committed to the confidentiality of information and will keep the database in its protection for five years. The research is in compliance with Resolution No. 466/2012 and No. 510/2016, of the National Health Council.

Given the urgency due to the COVID-19 pandemic and the unique opportunity for the immediate start of the research, priority will be requested in the agreement by the National Council for Ethics in Research (CONEP).

\section{Troubleshooting}

\section{Time Taken}

It will take 22 months total.

- The first month for project elaboration 
- Months 2, 3, 5 and 8 for questionnaire application

- Months $3,4,5,6$ and $10,11,12,13,14$ and 15 for data analysis

- Months for $3,4,10,11,12,13,14,15,16$ and 17 for elaboration of articles and submission to journals

- Months $14,15,16,17,18,19,20,21,22,23$ and 24 for presentation of results at scientific events

\section{Anticipated Results}

We aim to identify patterns of evolution (trajectories) of PTSD symptoms and also to document and report in real time the sample prevalence and severity of PTSD, depression and anxiety symptoms in the beginning, during, and in the decline of the pandemic.

We expect to verify sociodemographic risk factors related to the maladaptive personality traits associated with the trajectories of PTSD, distress, depression and anxiety symptoms and also to check the stability of the maladaptive traits of the personality during the pandemic; that is, to prove that such traits remain stable even during life events, or not.

We also search to relate the symptomatology with variables attributed to exposure to COVID19, such as contact with cases, having contracted the disease, being in regions of high incidence, being in quarantine/social isolation and others.

One of our main expected outcome is to check if symptoms presented by professionals who could not be quarantined during the indicated period (professionals from key areas such as health, cleaning, food, delivery sector, etc.) may be worse or different from those who were quarantined. Beyond that, we wish to see if the symptoms above related and other measures are, in some way, related to the ocupation group (students, health workers and students, security workers and so on).

\section{References}

AMERICAN PSYCHIATRIC ASSOCIATION. Manual diagnóstico e estatístico de transtornos mentais: DSM5. 5. ed. ed. Porto Alegre: Artmed, 2014.

BENSIMON, M. Elaboration on the association between trauma, PTSD and posttraumatic growth: The role of trait resilience. Personality and Individual Differences, v. 52, n. 7, p. 782-787, maio 2012. 
BLEVINS, C. A. et al. The Posttraumatic Stress Disorder Checklist for DSM-5 (PCL-5): Development and Initial Psychometric Evaluation. Journal of Traumatic Stress, v. 28, n. 6, 2015.

BRAMSEN, I.; DIRKZWAGER, A. J. E.; VAN DER PLOEG, H. M. Predeployment personality traits and exposure to trauma as predictors of posttraumatic stress symptoms: A prospective study of former peacekeepers. American Journal of Psychiatry, v. 157, n. 7, p. 1115-1119, 2000.

BREWIN, C. R.; ANDREWS, B.; VALENTINE, J. D. Meta-analysis of risk factors for posttraumatic stress disorder in trauma-exposed adults. Journal of consulting and clinical psychology, v. 68, n. 5, p. 748-766, 2000.

BROOKS, S. K. et al. The psychological impact of quarantine and how to reduce it: rapid review of the evidence. The Lancet, v. 395, n. 10227, p. 912-920, 2020.

CALEGARO, V. C. et al. The role of personality in posttraumatic stress disorder, trait resilience, and quality of life in people exposed to the Kiss nightclub fire. PLOS ONE, v. 14, n. 7, p. e0220472, 29 jul. 2019.

CENTERS FOR DISEASE CONTROL AND PREVENTION. History of Quarantine. Disponível em: <https://www.cdc.gov/quarantine/historyquarantine.html>. Acesso em: 29 mar. 2020.

CHO, G.-J.; KANG, J. Type D personality and post-traumatic stress disorder symptoms among intensive care unit nurses: The mediating effect of resilience. p. 1-10, 2017.

DAYTON, C. M. An introduction to latent class analysis. Handbook of longitudinal research: Design, measurement, and analysis, n. November, p. 357-372, 2008.

DUAN, W.; GUO, P.; GAN, P. Relationships among Trait Resilience, Virtues, Post-traumatic Stress Disorder, and Post- traumatic Growth. PLoS ONE, v. 10, n. 5, p. e0125707, 2015.

FEDER, A. et al. Risk, coping and PTSD symptom trajectories in World Trade Center responders. Journal of Psychiatric Research, v. 82, p. 68-79, nov. 2016.

FLETCHER, S.; O'DONNELL, M.; FORBES, D. Personality and trajectories of posttraumatic psychopathology: A latent change modelling approach. Journal of Anxiety Disorders, v. 42, p. 1-9, 2016.

HAWRYLUCK, L. et al. SARS control and psychological effects of quarantine, Toronto, Canada. Emerging Infectious Diseases, v. 10, n. 7, p. 1206-1212, 2004.

JAFFE, A. E. et al. Does it hurt to ask? A meta-analysis of participant reactions to trauma research. Clinical Psychology Review, v. 40, p. 40-56, 2015.

JAKSTĆ, N. et al. The role of personality traits in posttraumatic stress disorder (PTSD). Psychiatria Danubina, v. 24, n. 3, p. 256-66, 2012. 
JAMES, L. M. et al. DSM-5 personality traits discriminate between posttraumatic stress disorder and control groups. Experimental Brain Research, v. 233, n. 7, p. 2021-2028, 11 jul. 2015.

JHU. Johns Hopkins Coronavirus Resource Center. Disponível em:

<https://coronavirus.jhu.edu/map.html>. Acesso em: 29 mar. 2020.

JIA, X. et al. The effects of extraversion, social support on the posttraumatic stress disorder and posttraumatic growth of adolescent survivors of the Wenchuan earthquake. PLoS ONE, v. 10, n. 3, p. 113, 2015.

KIM, T. D.; LEE, S.; YOON, S. Inflammation in post-traumatic stress disorder (PTSD): A review of potential correlates of PTSD with a neurological perspective. Antioxidants, v. 9, n. 2, 2020.

KOTOV, R. et al. The Hierarchical Taxonomy of Psychopathology (HiTOP): A Dimensional Alternative to Traditional Nosologies. Journal of abnormal psychology, 2017.

KRUEGER, R. F. et al. Initial construction of a maladaptive personality trait model and inventory for DSM5. Psychological Medicine, v. 42, n. 09, p. 1879-1890, 2012.

KRUEGER, R. F. et al. The Personality Inventory for DSM-5-Brief form (PID-5- BF). Disponível em: $<$ http://www.psychiatry.org/practice/dsm/\%0Adsm5/online-assessment-measures>.

KRUEGER, R. F.; MARKON, K. E. The Role of the DSM-5 Personality Trait Model in Moving Toward a Quantitative and Empirically Based Approach to Classifying Personality and Psychopathology. Annual Review of Clinical Psychology, v. 10, n. 1, p. 477-501, 2014.

KUNST, M. J. J. Affective personality type, post-traumatic stress disorder symptom severity and posttraumatic growth in victims of violence. Stress and Health, v. 27, n. 1, p. 42-51, 1 fev. 2011.

LIMA, E. DE P. et al. Adaptação transcultural da posttraumatic stress disorder checklist 5 (PCL-5) e da life events checklist 5 (LEC-5) para o contexto brasileiro. Trends in Psychiatry and Psychotherapy, v. 38, n. 4, p. 207-215, 2016.

LIU, X. et al. Depression after exposure to stressful events: Lessons learned from the severe acute respiratory syndrome epidemic. Comprehensive Psychiatry, v. 53, n. 1, p. 15-23, 2012.

MANUELL, M. E.; CUKOR, J. Mother Nature versus human nature: Public compliance with evacuation and quarantine. Disasters, v. 35, n. 2, p. 417-442, 2011.

MATTSON, E.; JAMES, L.; ENGDAHL, B. Personality Factors and Their Impact on PTSD and Posttraumatic Growth is Mediated by Coping Style Among OIF/OEF Veterans. Military medicine, mar. 2018.

MILLER, M. W. et al. Oxidative stress, inflammation, and neuroprogression in chronic PTSD. Harvard Review of Psychiatry, v. 26, n. 2, p. 57-69, 2018. 
$\mathrm{NISHI}$ D. et al. Resilience, post-traumatic growth, and work engagement among health care professionals after the Great East Japan Earthquake: A 4-year prospective follow-up study. Journal of Occupational Health, v. 58, n. 4, p. 347-353, 2016.

NORRIS, F. H.; TRACY, M.; GALEA, S. Looking for resilience: Understanding the longitudinal trajectories of responses to stress. Social Science and Medicine, v. 68, n. 12, p. 2190-2198, 2009.

NYLUND, K. L.; MUTHÉN, B. O. Deciding on the Number of Classes in Latent Class Analysis and Growth Mixture Modeling: A Monte Carlo Simulation Study Karen. v. 14, n. 4, p. 1-36, 2011.

ORCUTT, H. et al. Prospective Trajectories of Posttraumatic Stress in College Women Following a Campus Mass Shooting. Journal of Traumatic Stress, v. 27, n. 3, p. 249-256, 2014.

ORNELL, F. et al. "Pandemic fear" and COVID-19: Mental Health Burden and Strategies. Brazilian Journal of Psychiatry, v. 0, n. 0, 2020.

OZER, E. J. et al. Predictors of posttraumatic stress disorder and symptoms in adults: A meta-analysis. Psychological Trauma: Theory, Research, Practice, and Policy, v. S, n. 1, p. 3-36, ago. 2008.

PENG, E. Y. C. et al. Population-based post-crisis psychological distress: An example from the SARS outbreak in Taiwan. Journal of the Formosan Medical Association, v. 109, n. 7, p. 524-532, 2010.

SELF-BROWN, S. et al. Posttraumatic stress disorder symptom trajectories in Hurricane Katrina affected youth. Journal of affective disorders, v. 147, n. 1-3, p. 198-204, maio 2013.

SHAKESPEARE-FINCH, J.; LURIE-BECK, J. A meta-analytic clarification of the relationship between posttraumatic growth and symptoms of posttraumatic distress disorder. Journal of anxiety disorders, $\mathrm{v}$. 28, n. 2, p. 223-9, mar. 2014.

SHIGEMURA, J. et al. Public responses to the novel 2019 coronavirus (2019-nCoV) in Japan: Mental health consequences and target populations. Psychiatry and Clinical Neurosciences, p. pcn.12988, 23 fev. 2020.

SILVA, T. L. G. DA et al. Psychometric properties of the Posttraumatic Growth Inventory in a sample of Brazilian university students. Trends in Psychiatry and Psychotherapy, v. 40, n. 4, p. 292-299, dez. 2018.

SPRANG, G.; SILMAN, M. Posttraumatic Stress Disorder in Parents and Youth After Health-Related Disasters. Disaster Medicine and Public Health Preparedness, v. 7, n. 1, p. 105-110, 25 fev. 2013.

SUN, L. et al. Prevalence and Risk Factors of Acute Posttraumatic Stress Symptoms during the COVID-19 Outbreak in Wuhan, China. medRxiv (preprint), 2020.

TAYLOR, M. R. et al. Factors influencing psychological distress during a disease epidemic: Data from Australia's first outbreak of equine influenza. BMC Public Health, v. 8, n. 1, p. 347, 3 dez. 2008. 
VIGNOLA, R. C. B.; TUCCI, A. M. Adaptation and validation of the depression, anxiety and stress scale (DASS) to Brazilian Portuguese. Journal of Affective Disorders, v. 155, n. 1, p. 104-109, 2014.

WANG, C. et al. Immediate Psychological Responses and Associated Factors during the Initial Stage of the 2019 Coronavirus Disease (COVID-19) Epidemic among the General Population in China. International Journal of Environmental Research and Public Health, v. 17, n. 5, p. 1729, 6 mar. 2020.

WELCH, A. E. et al. Trajectories of PTSD Among Lower Manhattan Residents and Area Workers Following the 2001 World Trade Center Disaster , 2003 - 2012. v. 11, n. April, p. 158-166, 2016.

WILSON, C. B. et al. Predator Exposure/Psychosocial Stress Animal Model of Post-Traumatic Stress Disorder Modulates Neurotransmitters in the Rat Hippocampus and Prefrontal Cortex. PLoS ONE, v. 9, n. 2, p. e89104, 14 fev. 2014.

WORLD HEALTH ORGANIZATION. WHO Director-General's opening remarks at the media briefing on COVID-19 - 11 March 2020. Disponível em: <https://www.who.int/dg/speeches/detail/who-directorgeneral-s-opening-remarks-at-the-media-briefing-on-covid-19--11-march-2020>.

XIANG, Y. T. et al. Timely mental health care for the 2019 novel coronavirus outbreak is urgently needed. The Lancet Psychiatry, v. 7, n. 3, p. 228-229, 2020.

ZATTI, C. et al. Tradução para o Português Brasileiro e validação do Personality Inventory for DSM-5, brief Form (PID-5-BF). Trends in Psychiatry and Psychotherapy (no prelo), 2020.

\section{Acknowledgements}

\section{Supplementary Files}

This is a list of supplementary files associated with this preprint. Click to download.

- PROJETOTRADUZIDOFORMATAD01.docx

- PROJETOTRADUZIDOFORMATAD01.docx 